\title{
GESTÃO DE ASSOCIADOS NO BRASIL: UMA PESQUISA EXPLORATÓRIA
}

\author{
MEMBERSHIP MANAGEMENT IN BRAZIL: AN EXPLORATORY STUDY \\ GESTIÓN DE MEMBRESÍA EN BRASIL: UN ESTUDIO EXPLORATORIO
}

\section{RESUMO}

A gestão de associados - como associações recrutam, engajam e mantêm membros - é um tema pouco explorado na literatura, mas relevante para gestores de associações. 0 objetivo desta pesquisa é entender como se dá a gestão de associados em associações brasileiras, quais são as práticas mais utilizadas por essas organizações e como elas variam em função de seu de tipo de membro - pessoa física (APF) ou jurídica (APJ). Para tanto, foi desenvolvida uma survey com questões sobre o perfil da associação e suas práticas de gestão associativa, contando com 99 respostas válidas - 42 APFs e 57 APJs. Como achados principais, tem-se que a diferença nas práticas de gestão de associados entre associações de base individual e metaorganizações é menor do que se poderia supor. A pesquisa também revelou a predominância de uma governança pouco competitiva, baseada no modelo de "democracia de chapa única", desafiando, assim, a validade da ideia de associações como "escolas de democracia".

PALAVRAS-CHAVE: Gestão de associados, gestão de associações, associativismo, metaorganizações, membresia.

Fernando do Amaral Nogueira - fernando.nogueira@fgv.br

Professor da Fundação Getulio Vargas, Escola de Administração de Empresas de São Paulo - São Paulo - SP, Brasil

Laís Atanaka Denubila - laisatanaka@yahoo.com.br

Mestre em Administração Pública e Governo pela Fundação Getulio Vargas, Escola de Administração de Empresas de São Paulo - São

Paulo - SP, Brasil

Rogério Scabim Morano - r.morano@uol.com.br

Professor da Universidade Federal de São Paulo - Diadema - SP, Brasil

Submetido 11.10.2016. Aprovado 27.11.2017

Avaliado pelo processo de double blind Review.

DOI: http://dx.doi.org/10.12660/cgpc.v22n73.64399 


\begin{abstract}
While there is not much research on membership management - how associations recruit, engage and maintain members - the subject is very relevant to association managers. The goal of this research is to understand how Brazilian associations carry out membership management and how these management practices can vary depending on membership type, i.e., individual (APJ) or organizational (APJ). We developed a survey with questions about the profile of the association and its membership management practices, and obtained 99 valid responses - 42 APFs and 57 APJs. Main findings include that the difference in membership management practices between individual-based organizations and meta-organizations is smaller than the literature led to infer. The survey also revealed the predominance of uncompetitive governance, based on the "single ticket democracy" model, thus challenging the validity of the idea of associations as "democracy schools".
\end{abstract}

Keywords: Membership management, association management, associativism, meta-organizations, membership.

\title{
Resumen
}

La gestión de membresía -cómo las asociaciones atraen, reclutan y mantienen miembros- es un tema poco explorado en la literatura, pero de importancia para los gestores de asociaciones. El objetivo de esta investigación es entender cómo se da la gestión de membresía, cuáles son las prácticas más utilizadas por las asociaciones brasileñas y cómo varían en función del tipo de miembro -individual (APF, por su sigla en portugués) u organización (APJ, por su sigla en portugués)-. Para ello, se desarrolló una encuesta con preguntas sobre el perfil de la asociación y sus prácticas de gestión asociativa, con 99 respuestas válidas. La principal conclusión es que la diferencia en las prăcticas de gestión de membresía entre las organizaciones individuales y las metaorganizaciones es menor de lo que se suponía. Asimismo, el estudio reveló el predominio de una gobernanza poco competitiva, basada en el modelo de "democracia de un solo partido", que desafía la validez de la idea de asociaciones como "escuelas de democracia".

Palabras-clave: Gestión de membresía, gestión de asociaciones, asociativismo, metaorganizaciones, membresía.

\section{INTRODUÇÃO}

Ainda que haja uma longa tradição de pesquisa sobre associações voluntárias vindo de muitas disciplinas acadêmicas, ainda temos muito a aprender sobre as suas práticas de gestão. A maioria dos estudos concentra-se nos membros (por que eles se juntam, participam ou deixam associações - Tschirhart, 2006) ou sobre órgãos de governança, estrutura, poder e tomada de decisões (Einarsson, 2012). Existem poucos estudos (como Harris, 1998) que tentam compreender associações como uma forma específica de organização, que apresenta desafios organizacionais e de gestão particulares, como que tipo de esforço é o mais eficaz para recrutar novos membros ou pre- venir a saída dos associados existentes.

Recentemente, Nogueira (2014) buscou identificar e analisar como se dão as práticas de gestão de associados - como recrutar, engajar e manter membros - em três associações brasileiras. A partir dos estudos de casos, o autor mapeou dezenas de práticas associativas, mas sem esgotar o assunto. Este artigo representa, assim, uma sequência em que se busca aprofundar o entendimento do tema da gestão de associados com nova abordagem metodológica, de cunho quantitativo.

Mas é necessário ainda precisar o que se pretende estudar. Se nos concentrarmos em membros, uma segunda questão se torna relevante: De que tipo de membro se está fa- 


\section{GESTÃO DE ASSOCIADOS NO BRASIL: UMA PESQUISA EXPLORATÓRIA}

lando? Indivíduos, organizações ou ambos? A revisão da literatura nos mostra que há mais foco em membros individuais, mesmo que haja um recente interesse nas chamadas metaorganizações - organizações cujos membros são outras organizações (Ahrne \& Brunsson, 2008). Ainda assim, poucos tentam comparar quais são as semelhanças e diferenças entre esses diferentes tipos.

Dessa forma, o objetivo desta pesquisa é entender como se dá a gestão de associados em associações brasileiras, quais são as práticas de gestão de associados mais utilizadas por essas organizações e como elas variam em função de seu de tipo de membro - pessoa física ou jurídica. Para tanto, foi desenvolvida uma survey com questões sobre o perfil da associação e suas práticas de gestão associativa, enviada tanto a associações de pessoas físicas quanto jurídicas. As respostas foram analisadas de forma exploratória utilizando-se de diferentes técnicas estatísticas, entre as quais as de cunho descritivo, teste-t e de correlação.

Este estudo se justifica pelo potencial de aprofundar os entendimentos teóricos sobre gestão de associações e também por trazer contribuições às práticas dos gestores associativos. Acredita-se também que é o primeiro levantamento acadêmico deste tipo com foco específico em associações no Brasil. Há uma larga tradição de estudos sobre associativismo no país (por ex. França Filho, 2004 e Ganança, 2006), mas quase não se encontram discussões sobre a gestão de associações com base na literatura organizacional, o que também justifica a relevância para o debate acadêmico em nosso país. Finalmente, é importante pelo contexto atual de maior pressão para a profissionali- zação das organizações da sociedade civil, em especial no Brasil (cf. Mendonça, Alves, \& Nogueira, 2013).

Após esta introdução, este trabalho apresenta uma seção de revisão teórica, focada na literatura sobre associações e sua gestão. Segue-se com uma breve seção de métodos, com descrições sobre a coleta e análise da survey. Os dados são, então, apresentados e analisados, e encerra-se o artigo com algumas considerações finais.

Revisão teórica: associações, gestão de associados e tipos de membros

Uma associação civil voluntária é aqui entendida como uma organização privada, sem fins lucrativos, constituída de maneira voluntária por uma base ativa de associados dedicados a promover uma causa ou um interesse comum por meio de processos internos de inspiração democrática (Anheier, 2005; Einarsson, 2012; Rego, 2010; Skocpol, 2003; Tschirhart, 2006; Warren, 2001).

Esses autores costumam justificar o interesse no estudo associativo por dois grandes tipos de efeito: no nível macro, as associações ajudariam a formar e renovar instituições democráticas. Para indivíduos, essas organizações funcionariam como "escolas de democracia" (conforme a famosa ideia de Tocqueville), formando cidadãos mais democráticos (Roßteustscher, 2000).

Para além de estudos interessados em efeitos societais do associativismo, há também uma longa tradição de pesquisa que busca entender por que pessoas se associam a tais organizações. Há três grandes correntes (Tschirhart, 2006): o ato associativo 
é motivado por autointeresse (análise de custo-benefício); por ideologia/altruísmo (para apoiar uma causa); e por capital social (ampliar vínculos de confiança). Einarsson (2012) propôs uma perspectiva que nos parece mais realista, ao argumentar que o ser associativo é multidimensional, sendo motivado, em alguma medida, pelas três razões acima.

Ainda que o interesse pelas associações seja antigo, a pesquisa sobre sua gestão é mais recente. Alguns dos estudos que se dedicam a esse tema incluem os de Harris (1998), Skocpol (2003) e Rego (2010). Em especial, Nogueira (2014) argumentou que é necessário desenvolver mais pesquisas que combinem os aspectos de gestão com a perspectiva mais ampla dos estudos associativos. Como exemplo, é notável que existam muitos artigos preocupados em entender por que pessoas se associam (e.g. Stolle \& Rochon, 2001) sem que haja interesse correspondente em entender quais são os esforços e práticas das associações em trazer novos associados.

Esta seção teórica passa agora a definir o que se entende por gestão de associado, um conceito ainda em construção. Em seguida, discute as possíveis diferenças existentes dependendo do tipo de associado se pessoa física ou jurídica, fechando com uma breve síntese da seção.

\section{GESTÃO DE ASSOCIADOS: UM CONCEI- TO EM CONSTRUÇÃO}

Como resposta ao desafio mencionado acima, usa-se o conceito de gestão de associados (conhecido no mundo profissional, em inglês, como membership management).
Este pode ser entendido como todo esforço feito por diferentes atores - conselheiros, gestores, equipe e associados - dentro da associação para recrutar, engajar, manter e lidar com a saída de associados (Nogueira, 2014).

Os poucos estudos encontrados que lidam com esses desafios concentram-se principalmente na área de Marketing. Essas pesquisas dão boas contribuições em termos de modelos conceituais, ainda que pouco discutam a relação entre a gestão do associado e a literatura sobre associações de maneira mais ampla.

Zuckerman e Kretovics (2003) propõem um modelo simples para entender recrutamento e retenção de sócios em clubes e fraternidades. Há quatro estágios no modelo: a consciência (sobre a existência da associação), a atração, filiação e retenção.

Um modelo mais complexo vem de Gruen, Summers e Acito (2000), com base em estudos de marketing de relacionamento. Eles queriam entender "how membership organizations can use marketing actions directly under their control to affect the commitment of their membership and the membership's collective relational behavior" (Gruen et al., 2000 , p. 35). Eles propõem que ações de marketing diferentes (como boa prestação de serviços, reconhecer a participação dos membros e aumentar a interdependência dos associados) ativam diferentes tipos de compromisso (normativo, de continuidade, afetivo) e, em seguida, diferentes tipos de comportamentos (retenção, participação, coprodução). Mesmo que eles enfatizem a multidimensionalidade do seu modelo (semeIhante a Einarsson, 2012), os resultados de 


\section{GESTÃO DE ASSOCIADOS NO BRASIL: UMA PESQUISA EXPLORATÓRIA}

suas pesquisas apontam para uma relação associativa muito instrumental: "membership increasingly is becoming short-term focused and espouses an attitude of 'what have you done for me lately?' " (Gruen et al., 2000, p. 44).

Roy e Berger (2007) dão menor ênfase a essa relação instrumental, proclamando que o conceito de "força de afinidade" é a chave para entender associações. Eles mencionam que, em associações que se reúnem em torno de uma causa, ações de marketing com foco instrumental (como brindes e descontos) ajudarão pouco para fortalecer a afinidade entre membro e a organização.

Concentrando-se em programas de afiliação a museus, Battachyara, Rao e Glynn (1995) e Battachyara (1998) salientam a importância da conexão entre a identidade do membro e da organização. Esta é uma observação importante, pois esses museus podem empregar diferentes estratégias para causar e reforçar esse processo de identificação, tais como dar oportunidades para os membros de declarar publicamente a sua adesão (assim contribuindo para a autodefinição dos membros) e promover a interação entre os membros mediada pelo museu (misturando-se, assim, com outras pessoas de perfil semelhante).

Ao revisar as contribuições da literatura de marketing, é interessante notar que elas mostram claramente como a relação entre os membros e a associação pode ser administrada, em vez de apenas ser "dada como certa" (taken for granted, como parece ser o caso na maior parte da literatura sobre associações). Mas também deve-se levar em conta que muitos desses estudos de marke- ting têm um pressuposto implícito de ver o membro como um cliente da associação a quem se presta serviço - em vez de ser seu "dono democrático", alguém com poder decisório e a quem se deve prestar contas (Hvenmark, 2010). Precisamos, portanto, de um conceito mais completo de gestão de associados. Como visto, neste artigo, a gestão de associados é definida como todo o esforço feito por diferentes atores - conselheiros, dirigentes, funcionários e membros - para recrutar, manter, envolver e desfiliar membros.

Propõe-se aqui que as práticas de gestão de associados ocorrem em quatro etapas principais, com base no modelo proposto por Zuckerman e Kretovics (2003) e utilizando as muitas referências discutidas nesta seção:

1) Recrutamento: Nesta fase, o objetivo principal é tornar a associação o mais conhecida possível, a fim de atrair o perfil desejado de membros potenciais e transformá-los em associados.

2) Engajamento: Esta etapa reúne todas as práticas que visam envolver os membros com as atividades principais da associação - governança, questões políticas, relacionamento entre membros e coprodução de produtos e serviços.

3) Manutenção: Esta fase tem como foco tarefas mais cotidianas, tais como a comunicação com os membros, coleta de dados, taxas associativas e assim por diante. Essas práticas cumprem as funções administrativas da relação associativa, sendo necessárias, mas não suficientes para possibilitar a permanência do associado na organização.

4) Saída: A etapa final lida com membros 
que estão solicitando seu desligamento ou estão sendo expulsos pela própria associação. Inclui todas as práticas que visam impedir sua saída ou, ao menos, tentar entender por que não fazem mais parte da organização.

O quadro a seguir detalha algumas das principais práticas realizadas em cada etapa, conforme descrito por Nogueira (2014):

Quadro 1. Lista das principais práticas de gestão de associados

\begin{tabular}{|c|c|}
\hline Etapa & Conjunto de práticas observadas \\
\hline 1. Recrutamento & $\begin{array}{l}\text { - Divulgação geral por meio de táticas de comunicação e marketing; } \\
\text { - esforços de atração (atendimento, reuniões, eventos); } \\
\text { - processo de filiação (verificação de documentos, indicação de pares); } \\
\text { - aprovação (decisão e validação por comitê ou órgão de governança); } \\
\text { - formalização e recepção (comunicação ao novo membro, reunião de } \\
\text { boas-vindas). }\end{array}$ \\
\hline 2. Engajamento & $\begin{array}{l}\text { - Incentivo ao envolvimento dos membros nos processos de governança } \\
\text { e na representação pública da associação; } \\
\text { - incentivo e apoio para que o membro se envolva na gestão, nas ativida- } \\
\text { des, nos produtos e nos serviços da associação; } \\
\text { - promoção da interação formal e informal entre associados (atividades } \\
\text { de networking); } \\
\text { - reconhecimento à participação do associado (homenagens, prêmios); } \\
\text { - monitoramento do comportamento ético dos associados. }\end{array}$ \\
\hline 3. Manutenção & $\begin{array}{l}\text { - Criação de canais e procedimentos de atendimento de demandas es- } \\
\text { pecíficas; } \\
\text { - gestão da comunicação associativa; } \\
\text { - coleta de informações sobre os associados; } \\
\text { - cobrança da contribuição associativa; } \\
\text { - oferecimento de serviços, produtos e benefícios para os associados. }\end{array}$ \\
\hline 4. Saída & $\begin{array}{l}\text { - Gestão do "limbo associativo"; } \\
\text { - solicitação de saída por parte do associado; } \\
\text { - decisão do desligamento; } \\
\text { - contato com ex-associados. }\end{array}$ \\
\hline
\end{tabular}

Fonte: Adaptado de Nogueira (2014). 


\section{GESTÃO DE ASSOCIADOS NO BRASIL: UMA PESQUISA EXPLORATÓRIA}

Acredita-se que este é um modelo mais complexo e realista da relação entre a associação e os seus membros. Tem também o objetivo de salientar que existem dois principais tipos de ações para gerenciar essa relação: as que visam engajar o membro - lidando, assim, com questões centrais, substantivas - e as que visam a manutenção organizacional - mais ligadas aos repetitivos atos cotidianos necessários para administrar a associação.

Dois tipos de associados: pessoas e organizações

Se há um foco claro na gestão da relação com o associado, pareceu-nos relevante buscar entender quais são as possíveis diferenças quando varia o tipo de associado - se pessoa física ou jurídica. Esse último tipo foi denominado por Ahrne e Brunsson (2008) de metaorganização: uma organização composta de outras organizações. As pesquisas iniciais (é um foco de estudo recente, de poucos anos) indicam diferenças de governança, autonomia, identidade e recursos (Ahrne \& Brunsson, 2008; Gulati, Puranam, \& Tushman, 2012; Königa, Schulteb, \& Endersec, 2012; Malets, 2010; Nogueira, 2014).

Ahrne e Brunsson (2008) foram pioneiros em apontar a especificidade das ditas metaorganizações. De acordo com os autores, metaorganizações são diferentes de organizações cujos membros são indivíduos por três razões principais:

1. Metaorganizações e seus membros competem pela autonomia organizacional (o direito de tomar decisões por conta própria) e identidade (o self organizacio- nal);

2. os membros são mais diferenciados e podem ser muito mais fortes e ter acesso a muito mais recursos do que a própria associação;

3. metaorganizações tendem a ser organizações mais fracas, já que costumam ter pouco poder para impor suas normas e regras sobre os seus membros.

Mas temos que ressaltar que eles falam sobre organizações com membros individuais em geral, e não especificamente associações. Os autores consideram uma empresa privada ou uma agência do governo uma organização cujos membros (gerentes, funcionários) são indivíduos (baseando-se em estudos organizacionais clássicos tais como March e Simon nos anos 1950 e 1960). Mesmo que todas as metaorganizações sejam consideradas associações, não há discussão clara sobre como (ou se) metaorganizações diferem das associações de base individual. Como aponta Malets (2010), falta, assim, uma demarcação mais clara das diferenças entre metaorganizações e associações cujos membros são indivíduos, já que boa parte das dificuldades que os autores citam também vale para outros arranjos associativos.

Argumenta-se aqui que as metaorganizações possuem muito mais semelhanças com outras associações do que com empresas e agências do governo, mas que também existem, sim, diferenças conforme o tipo de associado. Como exemplo, tem-se um dos pontos argumentados por Ahrne e Brunsson (2008). Em metaorganizações, o voto como forma de tomada de decisões é ainda mais complicado do que em outras associações, pelo fato de que os eleitores são represen- 
tantes de organizações e seus votos podem ser questionados pela sua organização de origem. Nesse sentido:

It is more difficult to persuade organizations than it is to persuade individuals. [...] Representatives can meet, of course, but even if the representative persuades one or more representatives of other member organizations, it will be far from certain that these representatives will succeed in persuading other members of their own organization who were not present at the meta-organization's discussion. (Ahrne \& Brunsson, 2008, p. 121)

Em resumo, a metaorganização e suas associadas tendem a competir e a, potencialmente, prejudicar uns aos outros. Os conflitos aparecem sobre quem deve fazer 0 que, quem está no comando e quem há de ter mais protagonismo (Ahrne \& Brunsson, 2008).

É possível também observar uma diferença no perfil da base associativa. Em associações de pessoas físicas, a base tende a ser mais equilibrada, com o poder bastante distribuído, ainda que possam existir associados com mais poder, recursos ou legitimidade. Há também grande potencial de novos associados dentro do perfil geral de membros da organização.

Já em associações de pessoas jurídicas, a maior diferenciação entre organizações costuma resultar em maior dependência de poucos e poderosos associados. Ademais, há menor potencial de novos associados, já que, em um dado campo, costuma haver mais indivíduos do que organizações (mais estudantes ou professores do que universidades, por exemplo).

\section{Considerações finais da revisão teórica}

Esta seção teórica teve três objetivos específicos.

Primeiramente, argumentar que associações são um tipo organizacional específico, resgatando alguns de seus estudiosos clássicos e mostrando lacunas na literatura - especialmente no que toca à gestão da associação e à relação com seus associados.

Em segundo lugar, construir o conceito de gestão de associados, desenvolvendo um modelo a partir de diferentes contribuições da literatura estrangeira. $O$ conceito dá os elementos fundamentais a serem investigados na pesquisa empírica.

Finalmente, apresentar as diferenças organizacionais encontradas na literatura conforme o tipo de associado - se pessoa física ou jurídica. A principal hipótese que resulta desta seção é que podem existir diferenças significativas na gestão de associados conforme seu tipo.

Passa-se agora ao capítulo metodológico, que apresenta os percursos percorridos para realização da pesquisa.

\section{METODOLOGIA}

Para a identificação, caracterização e aprofundamento conceitual das práticas de associados mais utilizadas por associações e metaorganizações, sob a perspectiva teórica e empírica, foi realizada pesquisa quantitativa envolvendo questionário fechado aplicado a diversas dessas entidades. 


\section{GESTÃo DE ASSOCIADOS NO BRASIL: UMA PESQUISA EXPLORATÓRIA}

\section{Definição da amostra}

Como não há um banco de dados público ou privado completo de associações e metaorganizações existente no país que possa servir de referência, primeiramente foram formadas duas listas de possíveis participantes da pesquisa a partir de buscas por palavras-chave na internet (variações em torno de "associação brasileira de" ou combinando associação com termos de setores e profissões expressivos), indicações de profissionais da área, e busca em sites de redes formais e informais da sociedade civil. A primeira lista dava conta de entidades focadas em associados do tipo pessoa física (APF) e a segunda do tipo pessoa jurídica (APJ).

Para constituição do banco de dados, as associações e metaorganizações foram selecionadas de acordo com os seguintes critérios:

- ser formalizada, com estatuto estabelecido;

- possuir governança associativa de jure e de fato, com a presença de associados que têm o direito de serem votados e votar nas assembleias gerais;

- não ser parte de estrutura federativa;

- ter atuação de considerável alcance (por exemplo, regional ou nacional), ser minimamente estruturada em termos de gestão e recursos humanos;

- ter apenas associados pessoas físicas ou jurídicas. No caso de possuir ambas as categorias, apenas uma dessas pode votar e receber votos na assembleia.

As opções acima se justificam em especial pela vontade de observar organizações minimamente comparáveis - priorizando as mais estruturadas, que supostamente já têm nível maior de profissionalização de sua gestão e devem demonstrar capacidade de executar várias das práticas de gestão de associados. Já a opção por não incluir associações que fazem parte de estrutura federativa dá-se pela hipótese de que a gestão de associados em federações é potencialmente diferente de outras associações independentes, o que poderia contaminar a amostra e dificultar a análise. Ainda que toda federação ou confederação seja, em geral, uma metaorganização, acredita-se que é um subconjunto do grupo maior de metaorganizações e que ainda precisa de maiores estudos dentro dessa abordagem conceitual.

Elaboração do questionário e coleta de dados

A coleta de dados foi realizada por meio de questionário eletrônico preenchido pela web (ferramenta "Survey Monkey"), entre junho e agosto de 2015. O questionário foi desenvolvido com base na literatura sobre gestão de associações, conforme detalhado na seção anterior, tendo duas versões: uma para APFs, outra para APJs, com pequenas variações em perguntas específicas (por exemplo, quanto ao perfil da associação apenas APFs tinham a opção de assinalar "associação profissional"). Sua versão final foi submetida a um pré-teste com oito especialistas. A ferramenta de coleta revisada foi, então, enviada à lista completa de associações dos bancos de dados.

O questionário foi dividido em duas seções. A primeira continha 15 perguntas voltadas a gerar estatísticas descritivas para qualifi- 
cação do perfil das associações e avaliação da representatividade da amostra de respondentes. A segunda, com 22 perguntas, teve como foco as práticas de associados e estruturadas por meio de escala Likert. Nessas questões, o respondente preencheu o grau de importância percebido de cada prática de gestão de associados (variando de 1/ pouco importante a $7 /$ muito importante, com a opção de 0 para sinalizar se a prática não é feita). A lista das práticas é um desenvolvimento do modelo apresentado na seção teórica e baseia-se, sobretudo, nas práticas descritas no Quadro 1.

\section{Aplicação e representatividade}

O banco de dados de possíveis respondentes gerado ao final da busca por associações e metaorganizações totalizou 291 registros, sendo 150 de APFs e 141 de APJs. Todas as entidades do banco de dados receberam o questionário. Foram obtidas 109 respostas, sendo 10 desconsideradas por estarem incompletas ou por desobedecerem a algum critério básico de seleção - em especial o de haver apenas um tipo de associado com participação efetiva na governança. Chegou-se, assim, a 99 respondentes válidos (34\% de taxa de resposta), das quais 42 APFs e 57 APJs.

A tabela a seguir apresenta a localização das associações participantes da pesquisa.

Tabela 1. Localização das associações respondentes

\begin{tabular}{|c|c|c|c|c|c|c|}
\hline Estado & APF & $\%$ APF & APJ & $\%$ APJ & Total & $\%$ total \\
\hline SP & 23 & $54,8 \%$ & 45 & $78,9 \%$ & 68 & $68,7 \%$ \\
\hline DF & 8 & $19,0 \%$ & 8 & $14,0 \%$ & 16 & $16,2 \%$ \\
\hline RJ & 3 & $7,1 \%$ & 3 & $5,3 \%$ & 6 & $6,1 \%$ \\
\hline RN & 1 & $2,4 \%$ & 1 & $1,8 \%$ & 2 & $2,0 \%$ \\
\hline MG & 2 & $4,8 \%$ & & & 2 & $2,0 \%$ \\
\hline SC & 2 & $4,8 \%$ & & & 2 & $2,0 \%$ \\
\hline RS & 2 & $4,8 \%$ & & & 2 & $2,0 \%$ \\
\hline RO & 1 & $2,4 \%$ & & & 1 & $1,0 \%$ \\
\hline Total & 42 & $100,0 \%$ & 57 & $100,0 \%$ & 99 & $100,0 \%$ \\
\hline
\end{tabular}

Qualificar a representatividade da amostra é um exercício difícil, já que não há base de dados geral das associações brasileiras. $\mathrm{O}$ mais próximo que se chega disso é a Fasfil, do IBGE (2012), que menciona a existência de mais de 280 mil associações sem fins lucrativos no Brasil em 2010. No entanto, como argumentado por Nogueira (2014), uma parte considerável dessas organizações é constituída legalmente como associação, mas não possui, na prática, vida associativa - não há um quadro atuante de membros, entrada de novos associados, participação expressiva na governança da organização. São organizações de base fechada, constituída apenas para obedecer minimamente à legislação, cuja governança é controlada ao redor de uma liderança expressiva ou de um pequeno grupo de sócios-fundadores. Os conceitos de ONGs ou de organizações filantrópicas de prestação de serviços assistenciais são a expressão desse tipo de organização - e é interessante observar que, em outros países, há diferenciação jurídica en- 


\section{GESTÃO DE ASSOCIADOS NO BRASIL: UMA PESQUISA EXPLORATÓRIA}

tre associação de base associativa (membership-based organizations) e ONGs em geral (charities, por exemplo). Assim, não é possível precisar nem estimar minimamente quantas das 280 mil associações de jure têm base associativa de fato.

No entanto, o que é indiscutível é que a amostra estudada tem números acima das médias para as organizações da sociedade civil brasileiras no que tange a indicadores de tamanho, como se verá na seção seguinte. Seja por orçamento ou por tamanho de equipe, a amostra deste estudo representa uma elite das organizações brasileiras - 0 que não é de surpreender, visto que, de acordo com a Fasfil, quase $3 / 4$ das organizações brasileiras não possuem nenhum funcionário registrado, contando exclusivamente com a dedicação de seus voluntários.

\section{Tratamento e análise de dados}

O questionário não exigiu preenchimento obrigatório de seus itens, gerando a necessidade do tratamento de dados faltantes antes da aplicação das várias técnicas de análise realizadas. Adotou-se o método de substituição pela média (Hair, Black, Babin, Anderson, \& Tatham, 2009) como forma de tratamento do banco de respondentes obtido.

As análises das respostas obtidas foram realizadas em duas etapas distintas: desenvolvimento e análise das estatísticas descritivas (Anderson, Sweeney, \& Williams, 2011) das APFs e APJs e comparação entre médias de registros não pareados e testes de correlação de Pearson (Hair et al., 2009) para verificação de diferenças e correlações/associações entre as diversas práticas de associados adotadas pelos respondentes, bem como de medidas de tamanho de porte organizacional.

\section{APRESENTAÇÃO DE DADOS}

Esta seção apresenta os principais dados da pesquisa. Em geral, optou-se por fazer comentários sobre a amostra como um todo, destacando diferenças entre APFs e APJs apenas quando significativas. Aos interessados em conhecer as tabelas completas, basta entrar em contato com os autores deste estudo.

\section{Perfil geral das associações}

As associações respondentes têm uma idade média de 25 anos, com a mais antiga tendo sido criada em 1930 e a mais recente, em 2014. A grande maioria tem abrangência nacional $(85,7 \%)$, seguida de internacional $(7,1 \%)$, o que ajuda a explicar que suas sedes se concentrem em São Paulo, Brasília e Rio de Janeiro, conforme já apresentado na seção metodológica.

Em termos de atuação, elas poderiam escoIher diferentes alternativas para definir seu propósito principal. Assim, 60,6\% declararam-se como uma associação representativa, em que os membros representam interesses de um grupo social particular. Em seguida, vieram as associações setoriais $(35,4 \%)$ e as ativistas $(24,4 \%)$, em que os associados se reúnem em torno de uma causa comum. $\mathrm{O}$ quarto e último grupo foi composto pelas associações profissionais por definição, apenas APFs puderam marcar essa opção.

Os segmentos e causas dos respondentes 
foram os mais variados possíveis, passando por associações de médicos, de centros de defesa de direitos, de juízes, de empresas de jogos eletrônicos, de pacientes de doenças específicas (lúpus, autismo), de captadores de recursos e de agências de regulação, entre outras. A lista completa de respondentes pode ser solicitada aos autores.

Para fechar a descrição de perfil, apresentam-se, a seguir, diversas medidas de tamanho da organização: orçamento, tamanho de equipe (profissional e voluntária) e número de associados. Baseando-se nas médias, a associação mais comum possui cerca de 12 profissionais, 25 voluntários, orçamento de $\mathrm{R} \$ 2,1$ milhões e 812 associados. Em quase todas as medidas, os valores para APJs são superiores aos das APFs. As APJs têm, em média, 14 profissionais, enquanto as APFs têm apenas 9 . No entanto, a relação se inverte no número de associados: a média nas APFs chega a 1597, bem acima da média de 249 associados nas APJs.

Uma medida relevante do perfil das associações é a composição de seu orçamento. Foi incluída no questionário uma pergunta sobre qual proporção das receitas da organização vinha especificamente da contribuição dos associados, o que é descrito pela literatura como uma medida importante da sustentabilidade das associações (Nogueira, 2014). Como se vê na tabela a seguir, há uma proporção significativa de associações que dependem de seus associados para gerar mais da metade de seu orçamento anual.

Tabela 2. Do orçamento anual, que proporção aproximada vem de taxas associativas?

\begin{tabular}{lcccccc}
\hline Proporção & \#APF & $\%$ & \#APJ & $\%$ & Total & $\%$ Total \\
\hline Até 5\% & 5 & $11,9 \%$ & 4 & $7,0 \%$ & 9 & $9,1 \%$ \\
De 5 a 10\% & 4 & $9,5 \%$ & 1 & $1,8 \%$ & 5 & $5,1 \%$ \\
De 10 a 30\% & 6 & $14,3 \%$ & 3 & $5,3 \%$ & 9 & $9,1 \%$ \\
De 30 a 50\% & 4 & $9,5 \%$ & 10 & $17,5 \%$ & 14 & $14,1 \%$ \\
De 50\% a 75\% & 5 & $11,9 \%$ & 10 & $17,5 \%$ & 15 & $15,2 \%$ \\
De 75\% a 100\% & 18 & $42,9 \%$ & 27 & $47,4 \%$ & 45 & $45,5 \%$ \\
Não responderam & 0 & $0,0 \%$ & 2 & $3,5 \%$ & 2 & $2,0 \%$ \\
\hline Total & 42 & $100,0 \%$ & 57 & $100,0 \%$ & 99 & $100,0 \%$ \\
\hline
\end{tabular}

Gestão de associados: uma visão geral

Apresentam-se, a seguir, as respostas a questões que buscaram qualificar como se dá a gestão de associados, sem ainda entrar nos detalhes das práticas específicas. Os principais assuntos incluem a estrutura para o relacionamento com os associados, governança, a visão do respondente sobre os motivos de entrada e saída do associado, entre outros pontos - todos vistos como relevantes a partir da literatura discutida an- teriormente. Entender esses pontos ajuda a qualificar as práticas que serão discutidas adiante.

A responsabilidade pela relação com associados é da cúpula organizacional

A diretoria ou o conselho são os principais responsáveis pela gestão dos associados $(50 \%)$, ainda que o gestor principal também apareça com uma proporção considerável (28\%). Destaca-se, ainda, que apenas 19\% 


\section{GESTÃo DE ASSOCIADOS NO BRASIL: UMA PESQUISA EXPLORATÓRIA}

das respondentes declaram ter um departamento ou cargo especificamente voltados ao relacionamento com o associado. É também responsabilidade do conselho ou da assembleia a aprovação de novos associados.

\section{Há poucas barreiras de entrada}

$87 \%$ declaram aceitar a maioria ou todos os candidatos - em especial as APFs, que se mostram mais acessíveis do que as APJs; $48 \%$ aprovam a entrada de novos associados em até uma semana, enquanto apenas $12 \%$ dizem levar mais do que três meses.

A causa como motivo para entrar, a falta de pagamento, para sair

Entre os motivos para se associar, destacam-se: acreditar na causa da associação $(72 \%)$, os benefícios oferecidos (55\%) e os contatos com uma rede de pessoas ou organizações com perfil semelhante (49\%). Já entre os motivos de saída, destacam-se a falta de pagamento $(53 \%)$ e o distanciamento da associação (17\%). Apenas $9 \%$ apontam possíveis problemas ou conflitos éticos. É interessante notar que dois terços das associações têm código de ética, mas apenas metade destas exige que os associados se comprometam formalmente a seguir seus códigos de conduta ao se tornarem membros.

A governança é dos associados, mas é uma democracia pouco competitiva

Os conselhos têm, em média, 12 integrantes, sendo a faixa mais comum entre seis e 15 vagas. Em sua grande maioria (93\%), são compostos exclusivamente por associados, ainda que nem todos possam participar: em $37 \%$ dos casos, apenas membros que cumprem certo requisitos previstos estatutariamente podem ser eleitos. No entanto, quando se entra nos detalhes do processo democrático, chama a atenção o fato da pouca competitividade eleitoral nas associações pesquisadas. Para $2 / 3$ das respondentes, a situação que mais descreve a governança usual da organização é a votação em uma chapa única, acordada previamente à assembleia. Como procedimentos competitivos, observam-se a votação individual e a existência de chapas concorrentes (em especial para APFs).

Gestão de associados: as práticas mais relevantes

Apresentam-se, a seguir, as práticas específicas de gestão de associados. Optou-se por colocar, no texto, as tabelas consolidadas (juntando APF e APJ), já que a comparação entre as médias será feita na próxima seção. São quatro tabelas, uma para cada conjunto: recrutamento, engajamento, manutenção e saída. Na primeira coluna, apresenta-se cada prática, na segunda, o número de respondentes que declarou fazer tal prática (em valores de 1 a 7 na escala Likert) e a coluna final mostra o valor médio das respostas - 0 que orientou a ordem de classificação das respostas.

\section{Recrutamento}

Como se vê na Tabela 3, as práticas mais significativas para trazer novos membros são claramente ligadas à comunicação, seja de modo mais geral, para tornar a organização mais conhecida, seja atendendo potenciais interessados. Destacam-se também as práticas ligadas ao processo de filiação em si - desde checar documentos e informações até aprovar e inserir o novo associado 
na rotina administrativa da organização (por exemplo, atualizando o banco de dados).

Tabela 3. Relevância das práticas de recrutamento para todas as associações

\begin{tabular}{lcc}
\hline Práticas de recrutamento & Freq. & Média \\
\hline Comunicação e marketing em geral & 93 & 5,2 \\
Eventos para divulgar a associação & 91 & 4,9 \\
Insere o novo membro na rotina de gestão da associação & 86 & 4,5 \\
Dá atendimento regular a potenciais novos membros & 84 & 4,4 \\
Verifica documentos e informações dos candidatos & 81 & 4,3 \\
Faz reuniões e convites para aproximação & 78 & 3,8 \\
Divulga publicamente a entrada do novo associado & 72 & 3,7 \\
Dá amostras de conteúdo, serviços etc. & 74 & 3,4 \\
Dá atenção especial ao novo associado & 62 & 2,9 \\
Faz pesquisas sobre candidatos a associados & 56 & 2,5 \\
Faz campanhas de associação & 59 & 2,4 \\
Envia um brinde ou presente de boas-vindas & 48 & 2,3 \\
Exige recomendação pelos pares & 46 & 2,2 \\
Faz uso de call-center ativo & 23 & 0,7 \\
\hline Respondentes & 99 & - \\
\hline
\end{tabular}

\section{Engajamento}

A tabela abaixo mostra quais são as práticas de engajamento mais praticadas e valorizadas pelos respondentes. Chama atenção a

\begin{tabular}{lcc}
\hline Práticas de engajamento & Freq. & Média \\
\hline Cria espaços informais de convivência & 82 & 4,1 \\
Escolhe associados para representação pública & 80 & 4 \\
Cobra respeito aos princípios éticos & 79 & 4 \\
Envolve os associados na gestão da associação & 84 & 4 \\
Cria programas formais e regulares de networking & 76 & 3,8 \\
Agradece a contribuição dos associados & 72 & 3,8 \\
Promove iniciativas em que um associado educa o outro & 69 & 3,4 \\
Faz consultas aos associados sobre questões de governança & 66 & 3,1 \\
Cria incentivos/alternativas para participar da assembleia & 60 & 2,8 \\
Aplica sanções/punições a comportamentos desviantes & 50 & 2,3 \\
Confere homenagens (cargo, prêmio, dá nome a serviço) & 54 & 2,3 \\
Secretaria ou apoia as atividades dos associados & 57 & 2,3 \\
Cria comissão de ética/conduta & 50 & 2,3 \\
Capacita quem se elege pela primeira vez & 36 & 1,2 \\
\hline Respondentes & 99 & - \\
\hline
\end{tabular}
alta pontuação de diversas práticas ligadas ao relacionamento e ao networking, em especial se comparadas a práticas ligadas à governança da associação.

Tabela 4. Relevância das práticas de engajamento para todas as associações 
Manutenção

O principal ponto a se destacar é que, em geral, a Tabela 5 é a que registra as mais altas médias entre as quatro que resumem as práticas de gestão de associados. Como será discutido adiante, isso talvez aconteça por reunir algumas das práticas mais comuns e tangíveis da gestão associativa, como a cobrança de taxa associativa, a prestação de contas aos associados e diversas atividades de comunicação voltadas a sua base de membros. É interessante notar, também, que muitas das práticas mais diretamente ligadas à ideia de que associados buscam basicamente benefícios estão entre as menos valorizadas.

Tabela 5. Relevância das práticas de manutenção para todas as associações

\section{Prática de manutenção}

Envia cobrança regularmente da taxa associativa

Presta contas aos associados

Faz ações de marketing e comunicação voltadas aos associados

Cria veículos de comunicação exclusivos aos associados

Cobre e divulga atividades da associação nos veículos exclusivos

Registra a participação de membros em atividades da associação

Cria e divulga materiais institucionais sobre a associação

Envia avisos de atraso do pagamento da taxa

Tem banco de dados de informações do associado

Cria políticas para atender a demandas comuns/regulares

Faz a gestão de comunidades on-line (com associados)

Negocia os valores para facilitar a quitação dos débitos

Envolve o associado como replicador de campanhas da associação

Oferece benefícios intangíveis, simbólicos (imagem)

Indica associados para falar com a imprensa

Faz uma gestão de uso da marca/logotipo com os associados

Mede a satisfação do associado em seus eventos e serviços

Oferece benefícios tangíveis, concretos (descontos, brindes etc.)

Realiza pesquisas sobre o perfil do associado

Oferece desconto para pagamento antecipado da taxa associativa

Segmenta benefícios ou serviços por categoria de associado

Respondentes

Freq. Média

$91 \quad 5,9$

$96 \quad 5,9$

$93 \quad 5,5$

$94 \quad 5,5$

$92 \quad 5,1$

$90 \quad 5,1$

$96 \quad 5,1$

$86 \quad 4,9$

$92 \quad 4,9$

$87 \quad 4,7$

$80 \quad 4,5$

$78 \quad 4,4$

$89 \quad 4,3$

$75 \quad 4,1$

$79 \quad 3,9$

$76 \quad 3,8$

$76 \quad 3,7$

$62 \quad 3,3$

$61 \quad 2,8$

$42 \quad 2$

$43 \quad 1,9$

$99 \quad-$

\section{Saída}

Finalmente, a tabela abaixo apresenta as pontuações para as práticas para lidar com 
Tabela 6. Relevância das práticas de saída para todas as associações

\begin{tabular}{lcc}
\hline Prática de saída & Freq. & Média \\
\hline Analisa pedidos de saída por parte do associado & 80 & 4,4 \\
Tenta uma reaproximação com os associados distantes & 78 & 3,8 \\
Desassocia membros inadimplentes ou inativos & 74 & 3,4 \\
Pesquisa com ex-associados os motivos do desligamento & 66 & 2,9 \\
Faz campanhas de reassociação & 55 & 2,2 \\
\hline Respondentes & 99 & - \\
\hline
\end{tabular}

\section{ANÁLISE DE DADOS}

Esta seção está dividida em duas partes. A primeira traz uma análise da correlação entre indicadores de tamanho das associações - um dos dados explorados que mais demonstraram relevância na hora de evidenciar diferenças entre APFs e APJs. A segunda apresenta análises estatísticas sobre diferenças nas práticas de associados em função do tipo de membro.

\section{Porte e correlações}

É razoável supor que os principais indicadores de porte organizacional estejam relacionados entre si. Uma primeira análise parece corroborar essa impressão, conforme a tabela a seguir.

Tabela 7. Correlação entre tamanho da equipe, orçamento e número de associados para todas as associações respondentes

\begin{tabular}{|c|c|c|c|c|}
\hline & & Equipe & Orçamento & Associados \\
\hline Equipe & & 1 & & \\
\hline Orçamento & & $0,669^{* *}$ & 1 & \\
\hline \multirow[t]{2}{*}{ Associados } & & $0,535^{\star *}$ & $0,422^{* *}$ & 1 \\
\hline & $N=99$ & ${ }^{* *}$ p-valor & & \\
\hline
\end{tabular}

É expressivo que as três correlações apresentem um valor considerável e se mostrem estatisticamente significativas. No entanto, se desdobramos essa análise entre APFs e APJs, nota-se uma variação importante. A correlação torna-se mais sólida para APFs (Tabela 8) e tem um efeito contrário para APJs (Tabela 9). 
Tabela 8. Correlação entre tamanho da equipe, orçamento e número de associados para as associações de pessoas físicas

\begin{tabular}{|c|c|c|c|}
\hline & Equipe & Orçamento & Associados \\
\hline Equipe & \multicolumn{3}{|l|}{1} \\
\hline Orçamento & $0,881^{* *}$ & \multicolumn{2}{|l|}{1} \\
\hline Associados & $0,837^{* *}$ & $0,909^{* *}$ & 1 \\
\hline & \multicolumn{3}{|c|}{${ }^{* *} \mathrm{p}$-valor $<0,01$} \\
\hline
\end{tabular}

Tabela 9. Correlação entre tamanho da equipe, orçamento e número de associados para as associações de pessoas jurídicas

\begin{tabular}{lccc}
\hline & Equipe & Orçamento & Associados \\
\hline Equipe & 1 & & \\
Orçamento & $0,557^{* *}$ & 1 & 1 \\
Associados & 0,079 & 0,039 & 1 \\
\hline \multicolumn{5}{c}{${ }^{* *}$ p-valor $<0,01$} \\
\hline
\end{tabular}

Esse achado parece confirmar o que foi proposto pela literatura: metaorganizações têm, potencialmente, um número pequeno de associados com grande capacidade de mobilização de recursos (Ahrne \& Brunsson, 2008). Enquanto em APFs a relação é proporcional - mais associados, mais equipe e orçamento -, em APJs isso não é necessariamente verdade. Há algumas associações com um número muito reduzido de associados dotados de um orçamento e de um tamanho de equipe considerável. Isso parece ser especialmente comum em algumas associações setoriais e industriais, que reúnem as grandes corporações do setor para representá-las coletivamente. Como exemplo, é possível encontrar, entre os res- pondentes, diversas APJs com menos de 20 associados e com orçamentos acima de $\mathrm{R} \$$ 3 milhões.

Práticas de associados: diferenças conforme o tipo de membro

Esta segunda seção apresenta o resultado de testes-t (Hair et al., 2009) em que se buscava comparar as médias de cada prática de gestão de associados conforme o tipo de membro, de modo a saber se possíveis diferenças podem ser atribuídas a essa variável.

A tabela a seguir apresenta as únicas variáveis em que a hipótese da diferença se mostrou aceitável, em termos estatísticos. 
Fernando do Amaral Nogueira - Laís Atanaka Denubila - Rogério Scabim Morano

Tabela 10. Práticas em que há diferença estatística conforme o tipo de membro

\begin{tabular}{|c|c|c|c|c|c|c|}
\hline \multirow{2}{*}{ Etapa } & \multirow{2}{*}{ Prática } & \multicolumn{2}{|c|}{ PF } & \multicolumn{2}{|c|}{ PJ } & \multirow{2}{*}{ Resultado } \\
\hline & & Média & $\mathrm{Dp}$ & Média & Dp & \\
\hline Recrutamento & $\begin{array}{l}\text { Verifica documentos e informa- } \\
\text { ções dos candidatos }\end{array}$ & 3,12 & 2,89 & 5,16 & 2,33 & Aceita* \\
\hline Recrutamento & $\begin{array}{l}\text { Dá atendimento regular a poten- } \\
\text { ciais novos membros }\end{array}$ & 3,83 & 2,89 & 4,75 & 2,63 & Aceita** \\
\hline Recrutamento & $\begin{array}{l}\text { Divulga publicamente a entrada } \\
\text { do novo associado }\end{array}$ & 2,60 & 2,81 & 4,58 & 2,71 & Aceita* \\
\hline Engajamento & $\begin{array}{l}\text { Cria programas formais e regula- } \\
\text { res de networking }\end{array}$ & 3,02 & 2,85 & 4,33 & 2,39 & Aceita $^{* * *}$ \\
\hline Manutenção & $\begin{array}{l}\text { Envia cobrança regularmente da } \\
\text { taxa associativa }\end{array}$ & 5,43 & 2,42 & 6,23 & 1,89 & Aceita** \\
\hline Manutenção & $\begin{array}{l}\text { Negocia os valores para facilitar a } \\
\text { quitação dos débitos }\end{array}$ & 3,38 & 3,03 & 5,08 & 2,50 & Aceita* \\
\hline Saída & $\begin{array}{l}\text { Analisa pedidos de saída por par- } \\
\text { te do associado }\end{array}$ & 3,60 & 3,05 & 5,04 & 2,36 & Aceita** \\
\hline Saída & $\begin{array}{l}\text { Desassocia membros inadimplen- } \\
\text { tes ou inativos }\end{array}$ & 2,81 & 2,70 & 3,75 & 2,69 & Aceita** \\
\hline Saída & $\begin{array}{l}\text { Pesquisa com ex-associados os } \\
\text { motivos do desligamento }\end{array}$ & 2,19 & 2,55 & 3,47 & 2,82 & Aceita* \\
\hline & \multicolumn{2}{|l|}{${ }^{*}$ p-valor $<0,05$} & p-valo & $<0,10$ & \multicolumn{2}{|c|}{${ }^{* * *}$ p-valor $<0,15$} \\
\hline
\end{tabular}

Vê-se, assim, que, em apenas nove das 50 práticas analisadas, houve diferença estatística significante. Caso se considerem apenas diferenças cujo $p$-valor seja de 0,05, somente quatro das nove variáveis apresentariam significância. Ainda que não fosse possível fazer previsões precisas no início da pesquisa - visto que a literatura ainda é incipiente e dado o desenho exploratório da survey -, esse baixo número pode ser considerado surpreendente.

Um último ponto a se destacar é que as pontuações médias para as APJs foram invariavelmente maiores do que nas APFs. Uma possível explicação talvez venha do tamanho médio das APJs, maior do que o das APFs. Nesse caso, talvez as pontuações mais altas sejam expressão de uma maior capacidade organizacional.

\section{CONSIDERAÇÕES FINAIS}

Este artigo propôs-se a entender como se dá a gestão de associados em associações brasileiras, quais são as práticas de gestão de associados mais utilizadas por essas organizações e como elas variam em função de seu tipo de membro - pessoa física ou jurídica. Após a realização de uma survey com 99 associações brasileiras, foi possível descrever, em considerável nível de deta- 


\section{GESTÃo DE ASSOCIADOS NO BRASIL: UMA PESQUISA EXPLORATÓRIA}

Ihes, qual o perfil das associações respondentes, quais são as características de sua estrutura organizacional voltada à relação com associados e quais são as práticas de gestão mais realizadas e mais valorizadas pelos respondentes.

De modo geral, a pesquisa traz mais evidências para validar o conceito de gestão de associados e o conjunto de práticas pelas quais essa gestão acontece. Se esse conceito emerge de estudos qualitativos, sua aplicação em pesquisa survey revela que, de fato, muitas das práticas encontradas em apenas três casos estão presentes no dia a dia de dezenas de associações brasileiras. Tende-se também a reforçar a ideia de que as associações - sejam elas de indivíduos ou de pessoas jurídicas - têm características organizacionais e desafios específicos de gestão que as separam em relação a outras formas organizacionais, como empresas, governos e mesmo ONGs - que podem até se constituir formalmente como associações, mas que, muitas vezes, não possuem vida e prática associativa. Esse é um ponto que merece mais atenção por parte de pesquisadores em estudos organizacionais e no campo da gestão social.

A pesquisa também revelou que a diferença nas práticas de gestão de associados entre associações de base individual e metaorganizações é menor do que se poderia supor, de acordo com a (pouca) literatura existente. É possível que parte da variação na adoção de práticas se explique por outros fatores, como porte organizacional.

O estudo ainda explicitou e quantificou a existência de "pequenas-grandes" associações de pessoas jurídicas, quando o pe- queno número de associados não limita o porte e o alcance dessas organizações. Isso é uma diferença marcante para as que têm pessoas físicas como associados, em que há uma correlação bem mais clara entre número de associados, orçamento e tamanho de equipe.

Finalmente, trouxe dados que ajudam a qualificar e quantificar como se dá a gestão em associações. Um, em especial, merece reflexão: a predominância de uma governança pouco competitiva, baseada no modelo de "democracia de chapa única". O que isso pode significar quando nos lembramos do peso que as associações têm como "escolas de democracia" em diversas correntes de teorias políticas, em especial as abordagens pluralistas?

Espera-se também que esta pesquisa possa dar uma contribuição específica aos gestores de associações, ao trazer conceitos, estatísticas e médias da prática associativa. Favorece-se, assim, a possibilidade de uma gestão mais baseada em dados, comparando os números de sua associação com as médias setoriais.

Entre os limites deste estudo, encontram-se as dificuldades de procedimentos metodológicos descritos na seção de métodos, em especial o desafio de saber da relevância e da representatividade da amostra selecionada. Além disso, é possível questionar se a pouca diferenciação entre a gestão de associações de indivíduos e metaorganizações resultou talvez de falhas na elaboração do questionário ou na análise das respostas.

Sugere-se, assim, que há espaço para a realização de novos estudos, tanto de cunho 
qualitativo como quantitativo, para aprofundar nossos conhecimentos sobre gestão associativa em geral, e sobre as práticas de associados, em específico. Finalmente, não se deve esquecer que existem também associações híbridas, cujos membros são tanto organizações como indivíduos. Ao longa da fase de formação de banco de dados, a quantidade de associações híbridas revelou-se muito maior do que inicialmente suposto, para surpresa dos pesquisadores. Eles foram excluídos da amostra por não atenderem aos critérios definidos, mas não resta dúvida de que há ainda muito para se entender sobre essas organizações - Como funciona a relação entre diferentes tipos de membros dentro de uma mesma associação?

\section{REFERÊNCIAS}

Ahrne, G., \& Brunsson, N. (2008). Meta-organizations. Cheltenham, UK: Edward Elgar Publishing Limited.

Anderson, D. R., Sweeney, D. J., \& Williams, T. A. (2011). Statistics for business and economics. USA: Boston, Cengage Learning.

Anheier, H. (2005). Nonprofit organizations: Theory, management, policy. London, UK: Routdledge.

Bhattacharya, C. (1998). When customers are members: Customer retention in membership contexts. Journal of the Academy of Marketing Science, 26(1), 31-44.

Bhattacharya, C., Rao, H., \& Glynn, M. A. (1995). Understanding the bond of identification: An investigation of its correlates among art museum members. Journal of Marketing,
59(4), 46-57.

Einarsson, T. (2012). Membership and organizational governance (Tese de doutorado, Stockholm School of Economics, Department of Management and Organization, Stockholm, Sweden).

França, G., Filho. (2004). A problemática da economia solidária: Um novo modo de gestão pública? Cadernos Ebape.Br, 2(1), 1-18.

Ganança, A. C. (2006). Associativismo no Brasil: Características e limites para a construção de uma nova institucionalidade democrática participativa (Dissertação de mestrado, Instituto de Ciência Política da Universidade de Brasília - UnB, Brasília, DF).

Gruen, T., Summers, J., \& Acito, F. (2000). Relationship marketing activities, commitment, and membership behaviors in professional associations. Journal of Marketing, 64(3), 34-49.

Gulati, R., Puranam, P., \& Tushman, M. (2012). Meta-organization design: Rethinking design in interorganizational and community contexts. Strategic Management Journal, 33(6), 571-586.

Hair, J. F., Jr., Black, W. C., Babin, B. J., Anderson, R. E., \& Tatham, R. L. (2009). Análise multivariada de dados (6a ed.). Porto Alegre, RS: Bookman.

Harris, M. (1998). Doing it their way: Organizational challenges for voluntary associations. Nonprofit and Voluntary Sector Quarterly, 27(2), 144-158.

Hvenmark, J. (2010). Members as democratic 


\section{GESTÃO DE ASSOCIADOS NO BRASIL: UMA PESQUISA EXPLORATÓRIA}

owners and profitable customers: On changing perceptions of membership and the commercialization of CSOs. In M. Freise, M. Pyykkönen, \& B. Vaidelytem (Eds.), A panacea for all seasons? Civil society and governance in Europe. Germany: Baden-Baden, Nomos Publishers.

IBGE, ABONG, GIFE, IPEA. (2012). As Fundações Privadas e Associações Sem Fins Lucrativos no Brasil: 2002, 2005 e 2010. Disponível em: <ftp://ftp.ibge.gov.br/Fundacoes_Privadas_e_Associacoes/2010/fasfl. pdf>. Acesso em: Dez. 2012.

Königa, A., Schulteb, M., \& Endersec, A. (2012). Inertia in response to non-paradigmatic change: The case of meta-organizations. Research Policy, 41(8), 1325-1343.

Malets, O. (2010). Book review: Göran Ahrne and Nils Brunsson: Meta-organizations. Organization Studies, 31(12), 1740-1744.

Mendonça, P., Alves, M. A., \& Nogueira, F. A. (Orgs.). (2013). Arquitetura institucional de apoio às organizações da sociedade civil no Brasil. São Paulo, SP: PGPC.

Rego, R. (2010). O impacto da profissionalização nas associações de consumidores: $\mathrm{O}$ caso da DECO. Revista Crítica de Ciências Sociais, (90), 113-132.

Roßteustscher, S. (2000). Associative democracy: Fashionable slogan or constructive innovation? In M. Saward (Ed.), Democratic innovation. deliberation, representation and association (Cap. 13, pp.172-183). Londres, UK: Routledge.

Roy, A., \& Berger, P. (2007). Leveraging Affiliations by Marketing to and Through Associations. Industrial Marketing Management, 36 (3), 270-284.

Skocpol, T. (2003). Diminished democracy: From membership to management in American civic life. Norman, USA: University of Oklahama Press.

Stolle, D., \& Rochon, T. (2001). Are all associations alike? Member diversity, associational type, and the creation of social capital. In Edwards, B., Foley, M. W., \& Diani, M. (Eds.).. Beyond Tocqueville: Civil society and the social capital debate in comparative perspective. USA: Lebanon, University Press of New England.

Tschirhart, M. (2006). Nonprofit membership associations. In W. Powell, \& R. Steinberg, The nonprofit sector: A research handbook. New Haven, USA: Yale University Press.

Warren, M. (2001). Democracy and association. Princeton, USA: Princeton University Press.

Zuckerman, R., \& Kretovics, M. (2003). Member acquisition and retention model. NASPA Journal, 41(1), 149-166. 